\title{
Stimulus and prefood stimulus effects on fixed-interval and fixed-ratio responding
}

\author{
PATRICK M. GHEZZI and CARL D. CHENEY \\ Utah State University, Logan, Utah
}

\begin{abstract}
The effects of superimposing a 10-sec stimulus (chamber illumination) at selected points during fixed-interval and fixed-ratio food-maintained responding were examined with rats. The stimulus either did or did not precede response-independent delivery of food. Responding during the initial portion of an interval or ratio was suppressed during the stimulus-alone, but was accelerated when the stimulus preceded food. Responding during the terminal portion of an interval or ratio was minimally suppressed during the stimulus, regardless of whether it did or did not precede food.
\end{abstract}

The term "negative conditioned suppression" refers to the reduction in the rate of food-maintained operant responding that occurs during a superimposed conditioned stimulus (CS) that terminates with an unconditioned stimulus (US), such as shock. The reduction in the rate of food-maintained operant responding that occurs during a CS that terminates with a US, such as food, has been termed "positive conditioned suppression" (Azrin \& Hake, 1969).

Exceptions to the general case of response suppression during preshock and prefood stimului have been reported. For example, Blackman (1968) found that responding maintained by a differential-reinforcementof-low-rate schedule of reinforcement increased in frequency during a preshock stimulus. The term "negative conditioned enhancement" is appropriate here, just as the term "positive conditioned enhancement" is appropriate in reference to response acceleration during a prefood stimulus (Meltzer \& Brahlek, 1970; Meltzer \& Hamm, 1974a, 1974b, 1978).

It turns out that the effect on responding during a preshock or foad stimulus is a function of both the schedule of reinforcement upon which the stimulus is imposed and the characteristics of such a stimulus, including its intensity, duration, location, modality, and relationship (see Henton \& Iverson, 1978, for review). The term "operant-Pavlovian interactions" (see Davis \& Hurwitz, 1977, and Schwartz \& Gamzu, 1977) reflects this confluence of conditioning processes.

One particularly interesting example of the interaction between operant- and Pavlovian-conditioning variables is found in the case of preshock stimuli superimposed on fixed-interval (FI) and fixed-ratio (FR) schedules of reinforcement. Lyon (1964) and Lyon \& Felton (1966) found that the effects of a preshock stimulus on

These data were presented at the meeting of the Western Psychological Association, San Francisco, April 1983. Reprints may be obtained from Patrick M. Ghezzi, Department of Psychology, UMC 28, Utah State University, Logan, Utah 84322.
FR responding depended on when the stimulus occurred relative to reinforcement: Responding early in the FR was suppressed during the stimulus, whereas responding late in the FR was unaffected. In a related study, Lyon and Millar (1969) found that FI responding was more severely suppressed during a preshock stimulus that occurred early in the FI than by one that occurred later. Thus, the results obtained with both FI and FR schedules suggest that the magnitude of suppression on these schedules is determined primarily by the temporal relationship between the onset of a preshock stimulus and its proximity to reinforcement.

Ghezzi and Miller (Note 1) showed that proximity to FI reinforcement was also critical when a prefood stimulus was used. However, in contrast with the Lyon and Millar (1969) result, responding early in the FI was enhanced during a 10 -sec prefood stimulus. Responding late in the FI was suppressed, but no more so than responding in the presence of a stimulus that did not end in a food US (i.e., CS-alone). Thus, despite the contrasting behavioral outcomes, it appears that the effects on FI responding of both preshock and prefood stimuli depend upon when these events occur relative to reinforcement. One might expect, on grounds of symmetry, that a pre-food stimulus superimposed on an FR baseline would also produce a different behavioral effect depending upon when it occurred relative to reinforcement. Such a finding would complete the generalization relating prefood and preshock stimulus effects to reinforcement proximity on FI and FR schedules.

This generalization would be strengthened further if it were also shown that the CS-US relation was actually responsible for the behavioral outcomes upon which the generalization is based. This of course raises the issue of Pavlovian control procedures (Rescorla, 1967). Unfortunately, the authors cited thus far (Lyon, 1964; Lyon \& Felton, 1966; Lyon \& Millar, 1969; Ghezzi \& Miller, Note 1) did not consider this issue. Thus, it is possible that the intrusion of, for example, a visual stimulus (Farmer \& Schoenfeld, 1966a, 1966b), or "free" food 
(Edwards, Peek, \& Wolfe, 1970; Shull \& Guilkey, 1976) or "free" shock (Azrin, 1959; Azrin \& Holtz, 1961; Dodd, Williams, Bissell, \& Weisman, 1977), during the course of FI or FR responding would produce the same reinforcement-proximity effect that has been attributed to CS-shock US and CS-food US relations. If so, it may be misleading to characterize prefood and preshock stimulus effects on FI and FR responding as examples of operant-Pavlovian interactions. On the other hand, it may be that these events do control FI and FR responding depending upon when they occur relative to operant reinforcement, but without the adequate control conditions, one cannot be certain.

The present study incorporated a traditional Pavlovian control procedure, namely CS-alone, in addition to a CS-food US-delayed conditioning procedure, in an effort to determine the effects that superimposing these events at selected points within the interval or ratio have on FI and FR responding.

\section{METHOD}

\section{Subjects}

Two male albino rats (Simonsen Laboratories, Inc.), about 120 days old at the start of the experiment, were maintained at approximately $80 \%$ of their free-feeding weights throughout the experiment.

\section{Apparatus}

A Lehigh-Valley two-lever (one lever removed) rat chamber contained within a ventilated, light- and sound-attenuating enclosure was used. A downward force of at least $10 \mathrm{~g}(.10 \mathrm{~N})$ was required to operate the lever. Pellets of food weighing $45 \mathrm{mg}$ (Bioserv, Inc.) were used as reinforcers.

A $10-W$ light, shielded by a yellow jewel and located midway between the food hopper and the chamber roof, illuminated the chamber throughout each experimental session (except during blackouts-see below). A $15-\mathrm{W}$ unshielded light located above the lever on the outside of the translucent Plexiglas chamber roof served as the CS. An exhaust fan at the side of the chamber provided an ambient noise level of approximately $60 \mathrm{~dB}$. A Foringer Model 1166-4 noise/click generator permitted delivery of auditory stimuli via a speaker located within the chamber enclosure. Conventional electromechanical equipment, located in an adjacent area, scheduled stimulus events and recorded responses.

\section{Procedure}

Following preliminary periods of food deprivation, magazine training, and shaping the leverpress, both subjects were exposed to a multiple FR 1 FR 1 schedule that, over the course of 14 consecutive sessions, was gradually changed to a multiple FR 100 FI 90-sec schedule. A continuous 70-dB tone served as the FR discriminative stimulus. In the absence of the tone, leverpressing was maintained by the FI schedule.

Each daily session began with an FR 100 component, followed by an FI 90-sec component series, and then back again to an FR series that was followed finally by another FI series. There were 10 reinforcers delivered within each component, for a daily total of $20 \mathrm{FR}$ and $20 \mathrm{FI}$ reinforcers. A 3-sec blackout period (i.e., chamber dark, lever inoperative) separated each component.

Both subjects were exposed to the multiple FR 100 FI 90 schedule for 10 consecutive sessions. Beginning with Session 11 , a 10 -sec stimulus (chamber illumination) was periodically super- imposed on both baseline schedules. For each of the two FR and two FI schedule components, the stimulus could occupy either the initial or the terminal portions of an interval or ratio. When the stimulus occurred during the initial portion of an interval or a ratio, it occupied the final $10 \mathrm{sec}$ of a 15 -sec period that began with reinforcement on the immediately preceding interval or ratio. When the stimulus occurred during the terminal portion of an interval, it occupied a 10 -sec period that began $75 \mathrm{sec}$ after reinforcement on the immediately preceding interval. When the stimulus occurred during the terminal portion of a ratio, it occupied the final $10 \mathrm{sec}$ of a 15 -sec period that began with completion of the 50th response.

Two stimulus presentations per schedule component, one at the initial portion and one at the terminal portion, were administered to both subjects during each session. Within each component, the decision as to which interval or ratio contained the stimulus was random, with the restriction that (1) the first and second interval or ratio within a component not contain the stimulus and (2) the stimulus never appear in more than one position within, or adjacent to, a particular interval or ratio.

For Subject A1, the 10-sec stimulus occurred as described for 60 consecutive sessions. For Subject A2, this control treatment lasted for 18 sessions. Sessions 19-57 (for Subject A2) and Sessions 60-78 (for Subject A1) constituted the "positive conditioned suppression" phase of the study. During these sessions, a single, response-independent $45-\mathrm{mg}$ food pellet was delivered upon termination of the stimulus. With this exception, the procedure employed during these sessions was identical to the immediately preceding control sessions wherein the stimulus occurred alone (i.e., CS-alone).

For Subject A2, Sessions 58-69 constituted a return to the CS-alone condition; that is, free-food no longer accompanied stimulus termination. Subject A1 was also returned to the CS-alone condition during Sessions 79-84. Subject A1 was subsequently returned to the positive conditioned-suppression phase for an additional 9 sessions (Sessions 85-93).

\section{RESULTS}

The data are represented in terms of an inflection ratio (Kamin, 1961), defined as $B /(A+B)$, where $B$ represents the response rate (responses per minute) during the 10-sec CS and A represents the response rate during the interval or ratio immediately preceding the CS, with the former matched to the latter in duration and location. The ratio can assume any value between 0 and 1.00 , with a value of .50 indicating equivalent response rates in the presence and absence of the CS. A ratio above .50 , or one below .50 , indicates, respectively, an increase, or a decrease, in response rate during the CS.

Mean inflection ratios, each calculated from three consecutive sessions, are shown in Figure 1 for Subject A1 and in Figure 2 for Subject A2. Points labeled "I" (filled circles) and points labeled " $T$ " (open circles) indicate, respectively, initial and terminal stimulus placement.

The first panel in Figure 1 shows, for Subject A1, the mean inflection ratios obtained during the final 9 (of 60 ) sessions of exposure to the CS-alone. The stimulus had a slight suppressive effect on both FR and FI initial and terminal response rates. When food was delivered upon termination of the stimulus (CS+US), initial FR, and especially initial FI, response rates were enhanced. Terminal FR and FI rates differed little from CS-alone levels. A return to the CS-alone condition reinstated the 


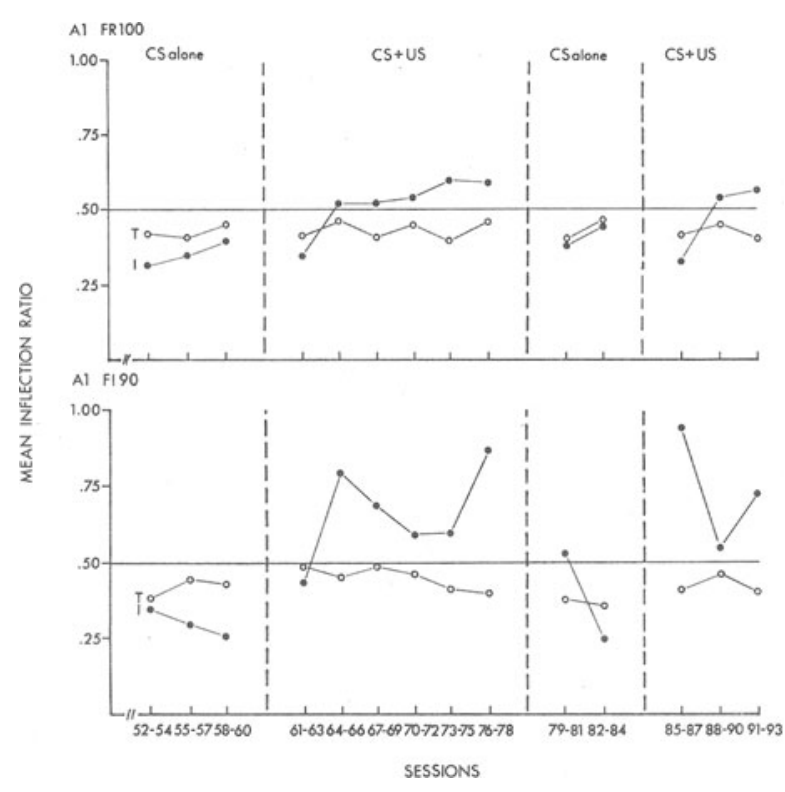

Figure 1. Mean inflection ratios obtained during the FR 100 (upper) and FI 90 (lower) schedules for Subject A1. Points labeled "I" (filled circles) and points labeled "T"' (open circles) represent, respectively, initial and terminal CS placements. Ratios above .50 and below . .50 indicate, respectively, increases and decreases in response rates during the $C S$.

suppression of initial FR and FI responding. Terminal FR and FI rates remained unaffected. A final return to the CS+US condition reestablished the initial FR and FI enhancement effect, and, again, terminal FR and FI rates were unaffected.

Figure 2 shows the mean inflection ratios for Subject A2. The final 9 (of 18) sessions of exposure to the CS-alone revealed nearly complete suppression of initial FR and FI responding. Terminal FR and FI rates were minimally suppressed. The subsequent addition of food upon termination of the stimulus (CS+US) enhanced both FR and FI initial rates throughout the duration of this phase. Terminal FR rates were uniformly unaffected. A brief period of response enhancement during the terminal FI CS eventually stabilized at a minimal level of suppression that differed little from CS-alone levels. A return to the CS-alone condition eliminated the initial FR and FI enhancement effect, and, again, there was little change in terminal FR and FI rates.

\section{DISCUSSION}

When a preshock stimulus is superimposed on an FR or FI schedule of food-maintained responding, its effect appears to depend upon when it occurs relative to reinforcement (Lyon, 1964; Lyon \& Felton, 1966; Lyon \& Millar, 1969). Likewise, when a prefood stimulus is superimposed on an FI schedule, as in this and the Ghezzi and Miller (Note 1) study, responding during the stimulus is different depending upon when it occurs relative to reinforcement. The present data indicate that a prefood stimulus superimposed on an FR baseline also will produce a different effect on responding, depending upon when it occurs in relation to reinforcement. Thus, the effects on FR- and FImaintained responding of preshock or prefood stimuli depend upon when these events occur relative to reinforcement. In spite of this, they do not produce the same behavioral outcome. A preshock stimulus that occurs early in a ratio or interval suppresses responding, but has little effect when it occurs later. In contrast, a prefood stimulus enhances responding when it occurs early, but, like a preshock stimulus, has a minimal effect when it occurs later.

The finding that preshock stimuli minimally affect terminal FR and FI rates is consistent with the findings of a number of related studies. Azrin (1959) and Dodd et al. (1977) found that shock presented late in an FR has only a minor effect on terminal rates. Similarly, Azrin and Holtz (1961) reported that terminal FI rates remained relatively stable despite the presentation of shock late in the interval. Although comparable studies involving food instead of shock are lacking, the results of the present study suggest that terminal FR and FI rates would be similarly unaffected. It therefore seems reasonable to conclude that close proximity to reinforcement on FR and FI schedules overrides the effects of various events, including preshock and prefood stimuli.

The situation appears quite different, however, when preshock or prefood stimuli occur early in an FR or FI. In the case of prefood stimuli, it is especially clear from the present study that a positive conditioned-enhancement effect occurs. It is suggested here and elsewhere (Ghezzi \& Miller, Note 1) that this effect relates to the similarity between extinction and the early, or post-reinforcement, period on fixed schedules of reinforcement (see Schneider, 1969, and Shull, 1979). Given that a prefood stimulus presented during extinction enhances responding (Estes, 1948; Morse \& Skinner, 1958; Reid, 1958), one would predict the enhancement effect observed in the present study.

In the case of a preshock stimulus, the evidence indicates suppression during the stimulus when it occurs early in a ratio or an interval. The present data indicate considerable suppres-

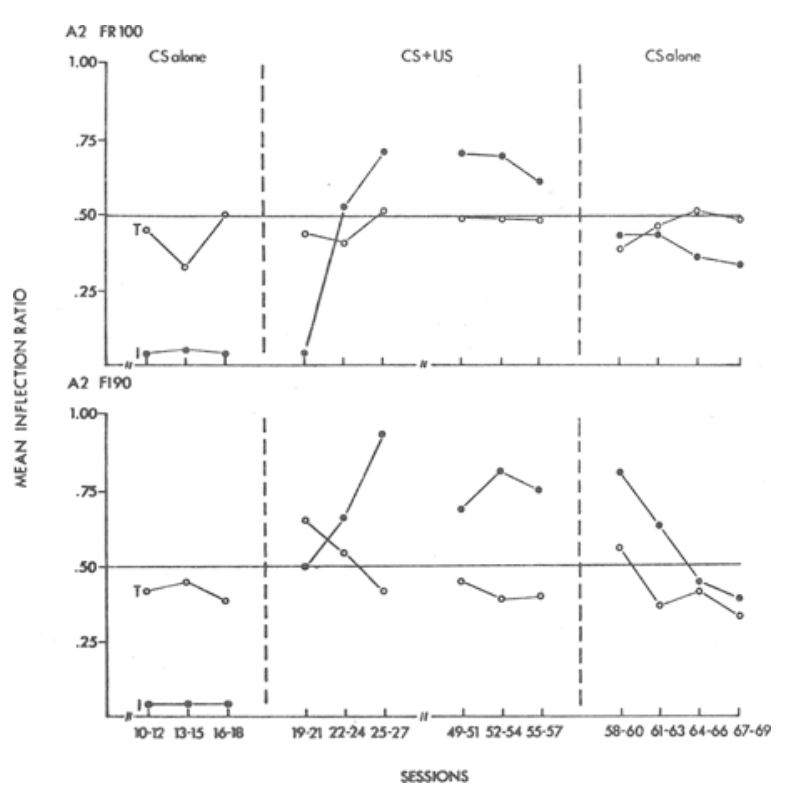

Figure 2. Mean inflection ratios obtained during the FR 100 (upper) and FI 90 (lower) schedules for Subject A2. Points labeled "I" (filled circles) and points labeled " $T$ " (open circles) represent, respectively, initial and terminal $\mathrm{CS}$ placements. Ratios above .50 and below .50 indicate, respectively, increases and decreases in response rates during the $C S$. 
sion of initial FR and FI responding during presentation of the CS-alone. The question arises regarding the extent to which behavior is already "suppressed" during the initial, or postreinforcement portion of an interval or ratio. It is certainly well known that a period of no responding occurs at this time (Ferster \& Skinner, 1957). Thus, it may be misleading to speak of negative conditioned suppression in this context.

Two final points concerning the reporting and conducting of research in this area deserve mention. First, in addition to the reporting of results in terms of suppression or inflection ratios, it is clearly of value to report response rates during CS and non-CS periods, particularly in view of the above comments regarding suppression of initial FR and FI rates during preshock stimuli. Moreover, as Davis (1981) pointed out, the effects on behavior may not be limited to periods in which the CS is present. Such effects may include changes in overall response rates and, in the case of FR and FI schedules, changes in the postreinforcement pause. The second point relates to the use of control procedures. With few exceptions, investigators of prefood stimulus effects have ignored control procedures, whereas investigators of preshock stimuli have not. The latter group has, in fact, contributed enormously to the understanding of Pavlovian conditioning and its control methodology (e.g., Rescorla, 1969; Rescorla \& Wagner, 1972). Investigators of prefood stimulus effects would be well advised to consider the issue of Pavlovian controls, for in their absence, it could be argued that very little is known about the effect on operant responding of a "true" (i.e., associative) Pavlovian appetitive-conditioning procedure.

\section{REFERENCE NOTE}

1. Ghezzi, P. M., \& Miller, L. Varying temporal placement of a prefood stimulus in a fixed-interval schedule. Paper presented at the meeting of the Rocky Mountain Psychological Association, Denver, April 1981.

\section{REFERENCES}

Azrin, N. H. Punishment and recovery during fixed-ratio performance. Journal of the Experimental Analysis of Behavior, 1959, 2, 301-305.

Azrin, N. H., \& Hake, D. F. Positive conditioned suppression: Conditioned suppression using positive reinforcers as the unconditioned stimuli. Journal of the Experimental Analysis of Behavior, 1969, 12, 167-173.

Azrin, N. H., \& Holtz, W. C. Punishment during fixed-interval reinforcement. Journal of the Experimental Analysis of Behavior, 1961, 4, 343-347.

Blackman, D. E. Conditioned suppression or acceleration as a function of the behavioral baseline. Journal of the Experimental Analysis of Behavior, 1968, 11, 53-61.

DAvis, H. On the importance of operant baselines in studies of operant-Pavlovian interactions. In C. M. Bradshaw, E. Szabadi, \& C. F. Lowe (Eds.), Quantification of steady-state operant behavior. Amsterdam: Elsevier/North Holland, 1981.

Davis, H., \& Hurwitz, H.M.B. Operant-Pavlovian interactions. Hillsdale, N.J: Erlbaum, 1977.

Dodd, P. W. D., Williams, S. M., Bissell, M. L., \& Weisman, R. G. Selective punishment early and late in fixed-ratio schedules of food reinforcement. Journal of the Experimental Analysis of Behavior, 1977, 27, 443-452.

Edwards, D. D., Peek, V., \& Wolfe, F. Independently delivered food decelerates fixed-ratio rates. Journal of the Experimental Analysis of Behavior, 1970, 14, 301-307.

Estes, W. K. Discriminative conditioning II: Effects of a Pavlovian conditioned stimulus upon a subsequently established operant response. Journal of Experimental Psychology, 1948, 38, 173-177.
Farmer, J., \& Schoenfeld, W. N. The effect of a responsecontingent stimulus introduced into a fixed-interval schedule of varying temporal placement. Psychonomic Science, 1966, 6, 15-16. (a)

Farmer, J., \& Schoenfeld, W. N. Varying temporal placement of an added stimulus in a fixed-interval schedule. Journal of the Experimental Analysis of Behavior, 1966, 9, 369-375. (b)

Ferster, C. B., \& Skinner, B. F. Schedules of reinforcement. New York: Appleton-Century-Crofts, 1957.

Henton, W. W., \& Iverson, I. H. Classical conditioning and operant conditioning. New York: Springer-Verlag, 1978.

Kamin, L. J. Trace conditioning of the conditioned emotional response. Journal of Comparative and Physiological Psychology, 1961, 54, 149-153.

LyoN, D. O. Some notes on conditioned suppression and reinforcement schedules. Journal of the Experimental Analysis of Behavior, 1964, 7, 289-292.

Lyon, D. O., \& Felton, M. Conditioned suppression and fixedratio schedules of reinforcement. Psychological Record, 1966, 16, 433-440.

Lyon, D. O., \& Millar, R. D. Conditioned suppression on a fixed-interval schedule of reinforcement. Psychonomic Science, 1969, 17, 31-32.

Meltzer, D., \& Brahlek, J. A. Conditioned suppression and conditioned facilitation with the same positive UCS: An effect of CS duration. Journal of the Experimental Analysis of Behavior, 1970, 13, 67-73.

Meltze R, D., \& HAMm, R. J. Conditioned enhancement as a function of the percentage of CS-US pairings and CS duration. Bulletin of the Psychonomic Society, 1974, 4, 357-362. (a)

Meltzer, D., \& Hamm, R. J. Conditioned enhancement as a function of the schedule of reinforcement. Bulletin of the Psychonomic Society, 1974, 3, 99-101. (b)

Meltzer, D., \& Hamm, R. J. Differential conditioning of conditioned enhancement and positive conditioned suppression. Bulletin of the Psychonomic Society, 1978, 11, 29-32.

Morse, W. H., \& Skinner, B. F. Some factors involved in the stimulus control of operant behavior. Journal of the Experimental Analysis of Behavior, 1958, 1, 103-107.

REID, R. L. The role of the reinforcer as a stimulus. British Journal of Psychology, 1958, 49, 292-309.

Rescorla, R. A. Pavlovian conditioning and its proper control procedures. Psychological Review, 1967, 74, 71-80.

Rescorla, R. A. Conditioned inhibition of fear. In N. J. Mackintosh \& W. K. Honig (Eds.), Fundamental issues in associative learning. Halifax: Dalhousie University Press, 1969.

Rescorla, R. A., \& Wagner, A. R. A theory of Pavlovian conditioning: Variations in the effectiveness of reinforcement and nonreinforcement. In A. H. Black \& W. F. Prokasy (Eds.), Classical conditioning (Vol. 2): Current research and theory. Englewood Cliffs, N.J: Prentice-Hall, 1972.

Schneider, B. A. A two-state analysis of fixed-interval responding in the pigeon. Journal of the Experimental Analysis of Behavior, 1969, 12, 677-687.

Schwartz, B., \& Gamzu, E. Pavlovian control of operant behaviors: An early analysis of autoshaping and of interactions between multiple schedules of reinforcement. In W. K. Honig \& J. E. R. Staddon (Eds.), Handbook of operant behavior. New Jersey: Prentice-Hall, 1977.

Shuld, R. L. The post-reinforcement pause: Some implications for the correlational law of effect. In M. D. Zeiler \& P. Harzem (Eds.), Reinforcement and the organization of behavior. New York: Wiley, 1979.

Shull, R. L., \& Guilkey, M. Food deliveries during the pause on fixed-interval schedules. Journal of the Experimental Analysis of Behavior, 1976, 26, 415-423.

(Manuscript received for publication May 28, 1983.) 